\title{
FORTRAN II - The First Computer Language Used at the University of Iceland
}

\author{
Oddur Benediktsson \\ Professor (Retired) University of Iceland \\ oddur@hi.is
}

\begin{abstract}
At the end of World War II, people considered Iceland an underdeveloped country. The use of IBM punched card systems started in 1949. The first computers appeared in 1964. Then the University of Iceland acquired an IBM 1620 "scientific" computer. The first computer language used to instruct engineers and scientists was FORTRAN II. The subsequent development gives an interesting picture of the advance of computer technology in Iceland.
\end{abstract}

Keywords: FORTRAN II, IBM 1620, programming education.

\section{Introduction}

The history of electronic data processing in Iceland extends back to 1949 when Hagstofa Íslands (Statistical Bureau of Iceland) obtained IBM unit record (punched card) equipment. By the early 1960s the Icelandic state, the municipalities, and the banks had developed a quite elaborate unit record data processing applications. The state and the town of Reykjavík established a joint data processing centre now called Skýrr. The first computers were installed in Iceland late in the year 1964; an IBM 1401 system at Skýrr and an IBM 1620 system to the University of Iceland [3, 8, 9].

With the acquisition of an IBM 1620 Model 2 computer in 1964, the University of Iceland entered the computer age. They introduced programming into the engineering curriculum the following year. The main programming language used was FORTRAN II. FORTRAN ${ }^{1}$ remained the first computer language taught to both engineering and science students at the University of Iceland for the ensuing two decades. "Although the IBM 1620 computer was extremely modest by modern standards, it had a profound impact on the use of computers in science, engineering and other fields in Iceland. It played a decisive role in the introduction to the computer age in Iceland" [9].

\section{Enters a Small Scientific Computer}

In 1959, IBM announced the IBM 1620 Model 1 data processing system, a small, transistorized scientific computer. It released the enhanced 1620 Model 2 in 1962.

\footnotetext{
${ }^{1}$ The early spelling "FORTRAN" is used in this text except when quoting names of the resent standards that use "Fortran".
} 
After a total production of about two thousand machines, the IBM 1620 was withdrawn late in 1970 [12]. Per Gerlöv, an engineer that started to work for IBM Denmark in 1960, states, "IBM 1620 was really the first personal computer. It was designed for computation intensive work and was normally programmed in FORTRAN. IBM Denmark ordered a "scientific" computer of the type IBM 1620 for demonstrations purposes. This machine had core memory of 20.000 decimals, and came with a FORTRAN compiler. The computer weighted ca. $600 \mathrm{~kg}$ and was sold for about 500.000 DKR or alternatively leased for 1.600 USD per month. This IBM 1620 demonstration machine was installed at IBM Denmark in 1961” [5].

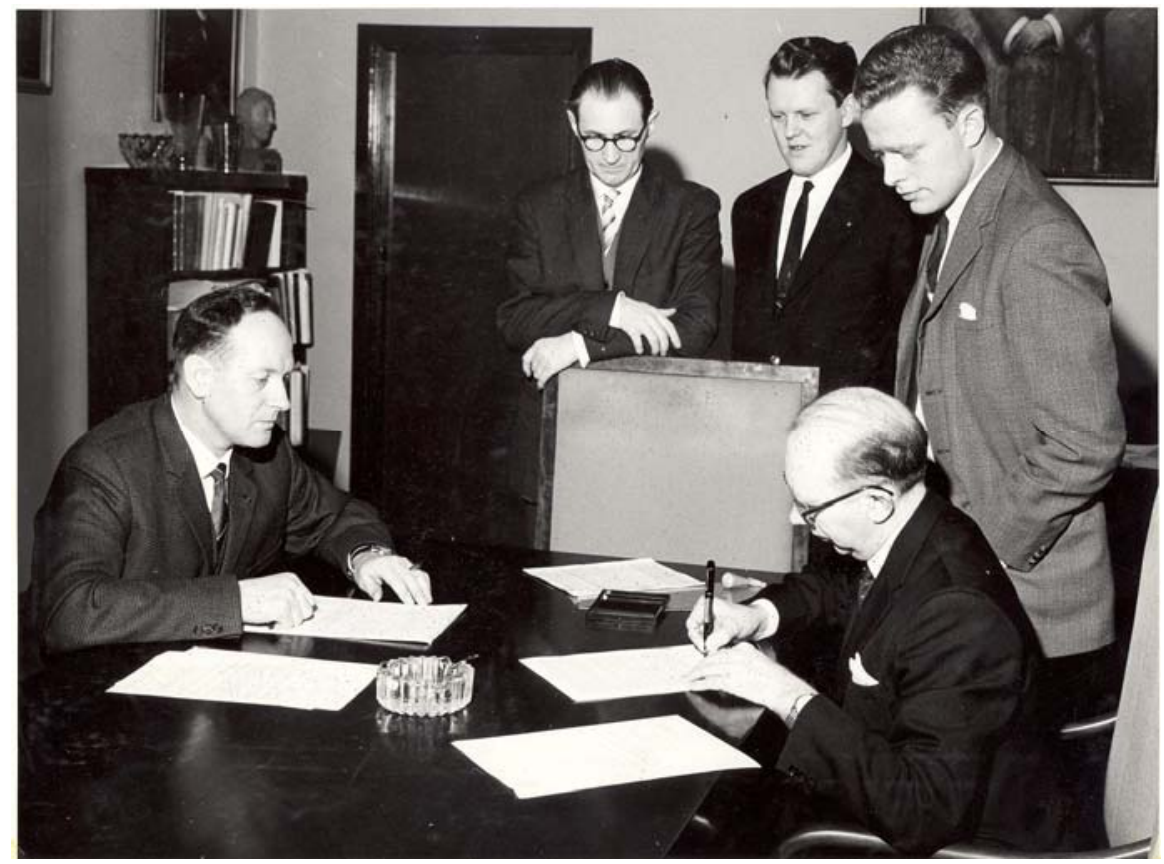

Fig. 1. The purchasing contract for the IBM 1620 being signed by the Rector Ármann Snævarr. Seated opposite Ottó A. Michelsen, the IBM representative in Iceland. Behind from left Trausti Einarsson, professor in geophysics, Magnús Magnússon, the head of the University Computing Centre, and Jóhannes L. L. Helgason, the financial director of the university. (From the Ottó A. Michelsen collection by the courtesy of University of Iceland Digital Library)

The IBM 1311 disk storage drive with removable disk packs was released in 1962 - "one of the most important new products we have ever announced" [7]. The 1620 Model 2 could be enhanced with the 1311 disk storage drives and with an early version of a disk operating system called Monitor I. "Monitor I, a collective name for four distinct but independent programs - Supervisor, Disk Utility, SPS II-D, and FORTRAN II-D programs - is a powerful, combined operating and programming system. Systems of this type have previously been available only on other largestorage capacity computers. The 1311 Disk Storage Drive with two-million positions of storage makes possible the implementation of such a system on the 1620 " [6]. 
University of Iceland acquired an IBM 1620 Model 2 computer late in the year 1964. The system was purchased as contrasted to being leased on monthly charges, as was the common practice in those days. As a result, the system was in use over a decade. Figure 1 shows the signing of the IBM 1620 contract.

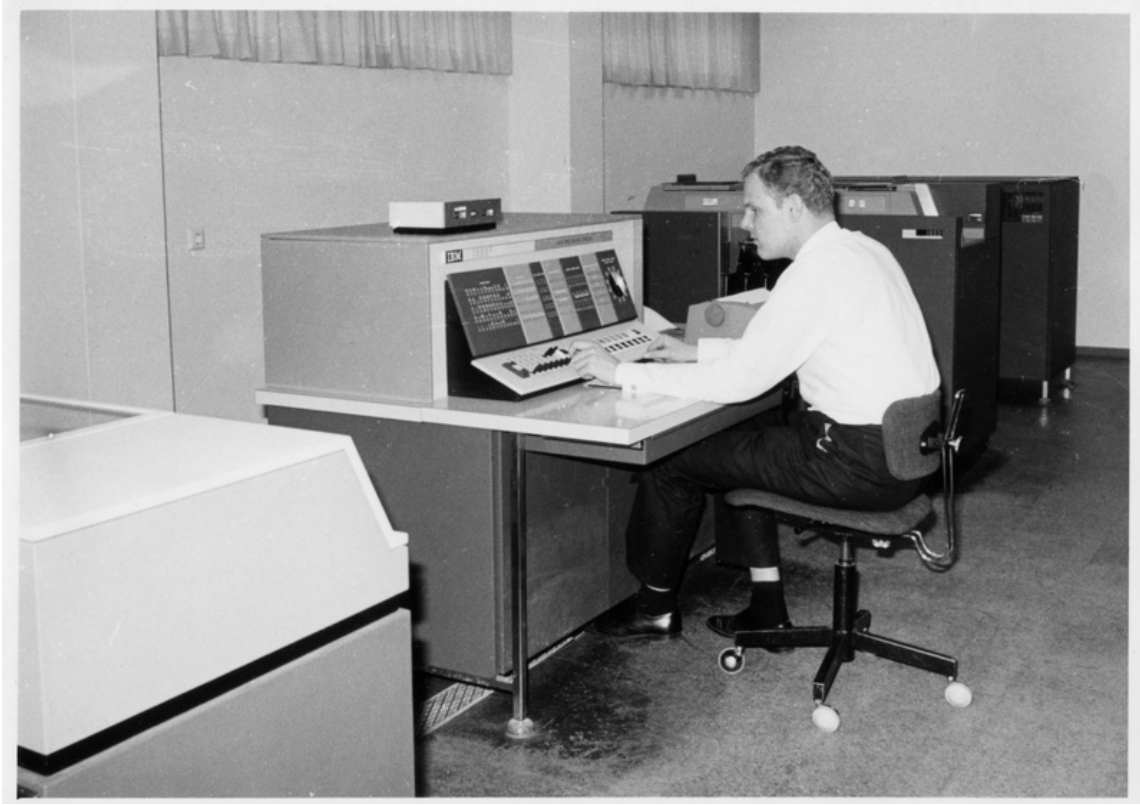

Fig. 2. The IBM 1620 configuration in 1967. Hördur S. Arinbjarnar is working at the console. A part of the IBM 1311 disk unite is to the left, IBM 1622 Card Read-Punch to the right and in the background the IBM 1625 Core Storage Unite housing the 40,000 digit magnetic core internal memory. (Photo by Dr. Thorsteinn Samundsson who was a staunch user of the 1620 and employed it to compute the Almanac for Iceland)

The acquired system had a magnetic core memory of 40 thousand "binary coded digits". The initial system was limited to input/output of programs via punched cards. The card reader/punch unit read cards at the speed of 250 cards per minute and punched cards at the rate of 125 . The original configuration had merely punched cards as input/output. However two 1311 magnetic disk storage units were soon added and subsequently a line printer making the system into a full fledged stand alone scientific computer - although with minute capacity in computational speed, internal and external storage capacity when compared to the computers at the time of this writing. Figure 2 shows the 1620 configuration before the printer was acquired.

\section{The Evolution of FORTRAN}

The development of the FORTRAN language started in the fifties. In late 1953, John W. Backus submitted a proposal to his superiors at IBM to develop a more efficient 
alternative to assembly language for programming their IBM 704 mainframe computer. A draft specification for The IBM Mathematical Formula Translating System was completed by mid-1954. This was an optimizing compiler, because customers were reluctant to use a high-level programming language unless its compiler could generate code whose performance was comparable to that of hand-coded assembly language" [11]. In fact indexing in the DO loop construct in FORTRAN (DO $35 \mathrm{I}=1$, $10 \ldots$ ) directly mirrors the use of index registers in the IBM 704 and hence the high performance of the translated program [5]. In the words of John W. Backus,

"To this day I believe that our emphasis on object program efficiency rather than on language design was basically correct. I believe that had we failed to produce efficient programs, the widespread use of languages like FORTRAN would have been seriously delayed... Unfortunately, we were hopelessly optimistic in 1954 about the problems of debugging FORTRAN programs (thus we find on page 2 of the Report, "Since FORTRAN should virtually eliminate coding and debugging...") and hence syntactic error checking facilities in the first distribution of FORTRAN I were weak. Better facilities were added not long after distribution and fairly good syntactic checking was provided in FORTRAN II" [2].

IBM's FORTRAN II appeared in 1958. The main enhancement was to support procedural programming by allowing user written subroutines and functions. These subprograms were relocatable at load time. Therefore, the door was open to develop libraries of reusable subprograms. This together with program portability is the key to successful and durable software development.

The 1620 FORTRAN II was two-pass compiler. An elaborate procedure was required to translate a FORTRAN II program on a 1620 punched card based system: The source code was punched into cards on an IBM 29 card punch machine. The deck of cards containing Pass 1 was read into the system followed by the deck of source code. The results of Pass 1 - the intermediate code - got punched into a deck of cards that is if the source code had been free of syntax errors. The deck of cards containing Pass 2 followed by the intermediate output was read in and the object code for translated program got punched out. Several deck of cards were then read in: A deck of cards containing program loader and object code for built in functions (SIN, COS, SQRT...) followed by the object code, again followed by previously compiled subprograms if any, and finally followed by the input data to be read by the program. The output of the program were punched to cards then to be listed on a line printer elsewhere. If the output was limited it could be listed on the console typewriter. Gunnar Thorbergsson, a now retired surveyor, used the IBM 1620 extensively. He describes aptly all the shuffling of card decks needed to run a large computational application on a card based 1620 system [10]. A commonly cited source indicates

“By 1960, versions of FORTRAN were available for the IBM 709, 650, 1620, and 7090 computers. Significantly, the increasing popularity of FORTRAN spurred competing computer manufacturers to provide FORTRAN compilers for their machines, so that by 1963 over 40 FORTRAN compilers existed. For these reasons, FORTRAN is considered to be the first widely used programming language supported across a variety of computer architectures" [11]. 
Even in those early days of computing, the portability and compatibility of programs had been recognized as a major challenge to the emerging software industry.

Perhaps the most significant development in the early history of FORTRAN was the decision by the American Standards Association (now ANSI) to form a committee to develop an "American Standard FORTRAN". The resulting two standards, approved 1966, defined two languages, FORTRAN (based on FORTRAN IV, which had served as a de facto standard), and Basic FORTRAN (based on FORTRAN II). The FORTRAN defined by the first standard became FORTRAN 66 [1]. FORTRAN 66 effectively became the first "industry-standard" version of FORTRAN. Subsequent standards FORTRAN 77, Fortran 90, FORTRAN 95, and FORTRAN 2003 have striven to follow the evolution in programming languages. For example, FORTRAN 2003 has objectoriented programming support: type extension and inheritance, polymorphism, dynamic type allocation, and type-bound procedures. FORTRAN is presently in widespread use for computational intensive applications in engineering and science. Vast libraries of subprograms exist [11].

\section{The First Programming Language at University of Iceland}

The first computer to reach Iceland was an IBM 1620 Model 1 system. "In October 1963, the IBM representative in Iceland arranged for an IBM 1620 Model I computer to make a "stop-over" in Iceland en route from Canada to Finland. We taught courses

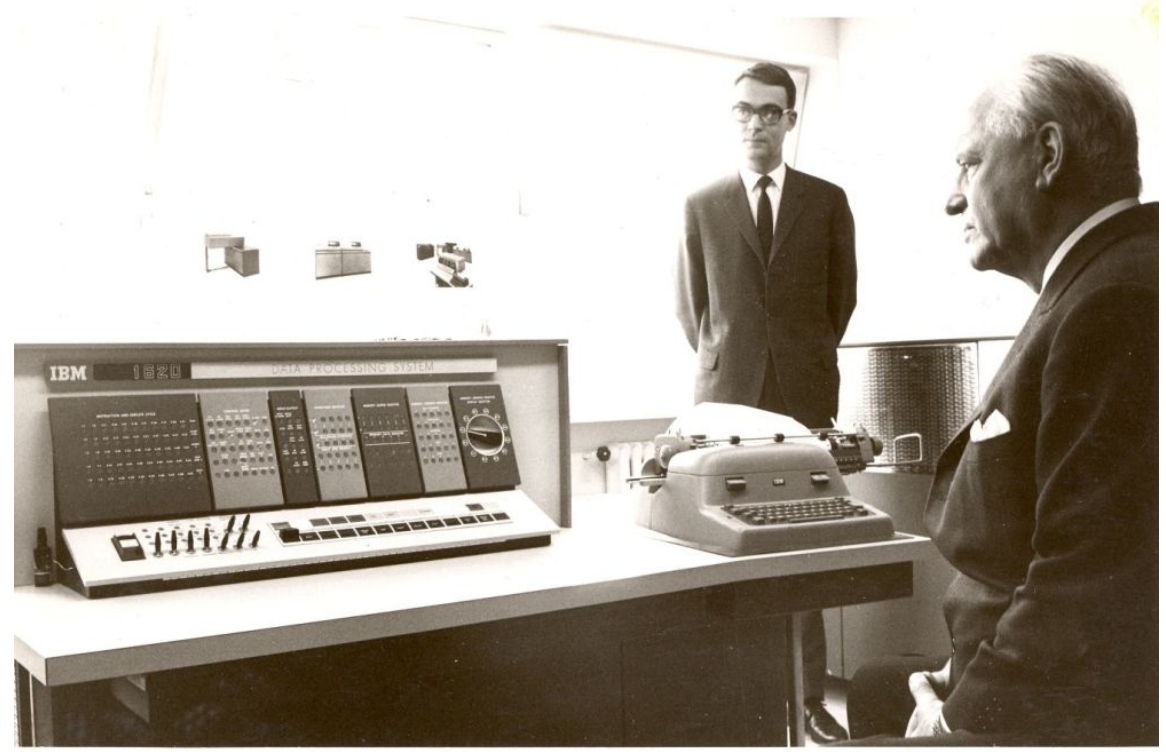

Fig. 3. IBM 1620 usage introduction held at IBM in Reykjavík in October 1963. The president of Iceland, Mr. Ásgeir Ásgeirsson (seated in foreground), showed deep interest in the first computer to reach Iceland. In the background is Mogens Hansen, Systems Engineer of IBM Århus, who came to Iceland to conduct FORTRAN courses. (From the Ottó A. Michelsen collection by the courtesy of University of Iceland Digital Library) 
in FORTRAN programming with support from IBM in Denmark and people had the opportunity to use the computer. This aroused great interest, primarily among scientists and engineers" [9]. Figure 3 was taken at this occasion.

Programming became part of the engineering curriculum in 1965. The programming language used was the 1620 FORTRAN II. Two computer science programs were initiated at the University in the science faculty in the early years: a BS degree program in computational mathematics was introduced in 1972 and a BS degree program in computer science introduced in 1976 [4].

Table 1 shows the first computer language taught to engineering and science students at the University and the computer systems used. It should be noted that computer application topics were being taught in other lines of studies of the University such as business administration, economics, library science, linguistics, and sociology.

Table 1 shows the typical evolution of the computer technology for a small university in a non-industrial country. The evolution starts with the single user IBM 1620 computer in the 1960s and continues with the multi user VAX-11 systems with numerous ASCII terminals in the 1970s and early 1980s. At the time of this writing in the year 2007 most every student owns a PC that is networked in the classroom and at home with so to speak unlimited capacity for computation and storage. The machines have access to a host of local servers together with the seemingly unlimited resources of the web.

We can now easily program applications as in multimedia, network access, database management, and mobile technology in Java and other languages on a PC. These applications were unimaginable on the 1620 FORTRAN II environment in the 1960s. Indeed, people could not have even conceived most of the current applications in the 1950 s.

Table 1. The first programming language and the computers used

\begin{tabular}{lll}
\hline \multicolumn{1}{c}{ Period } & Computer System & First Language \\
\hline $1965-1975$ & IBM 1620 & FORTRAN II \\
$1976-1978$ & IBM 360/30 and PDP 11 & FORTRAN IV \\
$1979-1982$ & DEC VAX-11 & FORTRAN 77 \\
$1983-1986$ & DEC VAX-11 and PCs on net & FORTRAN 77 and Modula-2 \\
$1987-1990$ & DEC VAX-11 and PCs on net & FORTRAN 77 and Turbo Pascal \\
$1990-1996$ & Unix servers and PCs on net & C++ and Turbo Pascal \\
$1997-2006$ & Unix servers and PCs on net & Java and MATLAB \\
\hline
\end{tabular}

\section{Conclusion}

At the end of World War II Iceland was an underdeveloped country. The economy was based mainly on fishing and farming. In contrast to its recent past, by many of the standard measures Iceland is now one of the most affluent countries in the world. Information technology has played a large part in this transformation. The society 
was able to shunt industrial revolution and enter into the modern day information age directly. This evolution is at least partly mirrored by Table 1 that reflects the development of scientific computer technology in the last four decades.

\section{References}

[1] ANSI X3.9-1966. USA Standard FORTRAN. American National Standards Institute. (Informally known as FORTRAN 66)

[2] Backus, J.: The History of FORTRAN I, II, and III. In: ACM SIGPLAN History of Programming Languages Conference, SIGPLAN Notices, vol. 13, pp. 165-180 (1978)

[3] Benediktsson, O., et al.: Computerisation of the Icelandic State and Municipalities: 1964 to 1985. In: Bubenko Jr., J., Impagliazzo, J., Sølvberg, A. (eds.) History of Nordic computing: IFIP WG9.7 first working conference on the history of Nordic computing (HiNC1), Trondheim, Norway, June 16-18, 2003. Springer, Heidelberg (2005)

[4] Benediktsson, O.: Early Curricula in Computer Science at the University of Iceland. In: Bubenko Jr., J., Impagliazzo, J., Sølvberg, A. (eds.) History of Nordic computing: IFIP WG9.7 first working conference on the history of nordic computing (HiNC1), Trondheim, Norway, June 16-18, 2003. Springer, Heidelberg (2005)

[5] Gerlöv, P.: Personal communication. Copenhagen 13 (October 2007)

[6] IBM 1620 Monitor I System Reference Manual. IBM System Reference Library. File No. 1620-36. Form C26-5793-4 (1965)

[7] IBM Data Processing Division chronology, http: / / www-03.ibm.com/ibm/history/exhibits / dpd50/ dpd50_chronology.html (Accessed April 7, 2007)

[8] Kjartansson, O.: Data Processing with Unit Record Equipment in Iceland. Mentioned in this volume titled History of Nordic Computing 2, Turku (2007)

[9] Magnusson, M.: The Advent of the first General Purpose Computer in Iceland and its Impact on Science and Engineering. In: Bubenko Jr., J., Impagliazzo, J., Sølvberg, A. (eds.) History of Nordic computing: IFIP WG9.7 first working conference on the history of nordic computing (HiNC1), Trondheim, Norway, June 16-18, 2003. Springer, Heidelberg (2005)

[10] Thorbergsson, G.: Early use of computers for adjusting triangulation in Iceland. Mentioned in this volume titled History of Nordic Computing 2, Turku (2007)

[11] Wikipedia, FORTRAN, http://en.wikipedia.org/wiki/FORTRAN (Accessed April 6, 2007)

[12] Wikipedia, IBM 1620, http://en.wikipedia.org/wiki/IBM_1620 (Accessed April 6, 2007) 